\title{
Relationships, environment, health and development: The information needs expressed online by young first-time mothers
}

Ian Ruthven, Steven Buchanan and Cara Jardine

Department of Computer and Information Sciences

University of Strathclyde

United Kingdom

ian.ruthven@strath.ac.uk, steven.buchanan@strath.ac.uk, cara.jardine@strath.ac.uk

This is the peer reviewed version of the following article: Ruthven, I. , Buchanan, S. and Jardine, C. (2018), Relationships, environment, health and development: The information needs expressed online by young first-time mothers. Journal of the Association for Information Science and Technology, 69: 985-995, which has been published in final form at https://doi.org/10.1002/asi.24024. This article may be used for non-commercial purposes in accordance with Wiley Terms and Conditions for selfarchiving. 


\begin{abstract}
This study investigates the information needs of young first time mothers through a qualitative content analysis of 266 selected posts to a major online discussion group. Our analysis reveals three main categories of need: needs around how to create a positive environment for a child, needs around a mother's relationships and well-being and needs around child development and health. We demonstrate the similarities of this scheme to needs uncovered in other studies and how our classification of needs is more comprehensive than those in previous studies. A critical distinction in our results is between two types of need presentation, distinguishing between situational and informational needs. Situational needs are narrative descriptions of a problematic situations whereas informational needs are need statements with a clear request. Distinguishing between these two types of needs sheds new light on how information needs develop. We conclude with a discussion on the implication of our results for young mothers and information providers.
\end{abstract}




\section{Introduction}

Motherhood is a significant life change that creates information needs across a range of topics and raises new needs regarding support, socialisation and relationships (Carolan, 2007; Loudon, Buchanan, \& Ruthven, 2016; Robb, McInery, \& Hollins Martin, 2013). There are many sources of information available to new mothers who have to choose how to use these different sources and which sources to use for which needs. Several studies have shown that the social networks of family and friends are more commonly used than formal information sources (Berkule-Silberman, Dreyer, Huberman, Klass, \& Mendelsohn, 2010; Leahy-Warren, McCarthy, \& Corcoran, 2012; Loudon et al., 2016) with other mothers being a particularly strong source of information, support and advice (Johns \& English, 2014; Loudon et al., 2016). Relationships with professionals vary greatly from episodic, needs-based interactions with family doctors who are seen as highly trusted as information sources but not often accessed for information (Loudon et al., 2016) to closer relationships with other professionals such as midwives (McKenzie, 2010).

Increasingly, online discussion groups and Internet forums play a strong role in providing support as such groups can provide a variety of opinions, transcend social constraints, and via anonymity, facilitate information seeking on sensitive topics. Drentea and Moren-Cross (2005) argued that, in addition to information provision, forums allow mothers to get emotional support that is often unavailable in more clinical environments. Brady and Guerien (2010) also discuss advantages relating to social support, in spite of the sometimes heated debate that can occur in online environments, and forums have been cited as constructive environments for mothers to gain social capital (O'Mahen et al., 2013).

A particular gap in the literature is surrounding the needs of young mothers (aged 21 or under) and their use of Internet forums. This group faces particular challenges in transitioning to motherhood, not least the stigma that young motherhood often attracts (Yardley, 2008). Our study, examining 266 posts from posters aged 14-21, offers a detailed account of the information needs posed by young first-time mothers through their posts to dedicated Internet discussion groups, uncovers new types of needs not present in other studies, and discusses the challenges often faced by young mothers in asking for information.

\section{Literature review}

\section{Information needs in motherhood}

Motherhood is a major life event which can affect all areas of a woman's life (Darvill, Skirton, \& Farrand, 2010). Many authors have recognised the significance of this life transition and its impact not just on the practical areas of life but also on a woman's identity, her priorities and life goals. Abrams 
and Curran (2011), for example, write about motherhood as a process that entails 'constructing a new conception of self, acquiring and mastering new behaviors and skills' and Martell (2001) talks about a process of 'Heading toward the new normal... a process through which these women were reorganizing their lives as mothers', recognising that motherhood cannot be compartmentalised but has to be integrated across a woman's whole life. As with other major life transitions there is a high level of uncertainty involved in pregnancy and motherhood and, as pregnancy develops, a move from vague, imagined outcomes to more concrete reality of what specific motherhood will mean. Therefore women have to adjust from one, understood, way of living to prepare for a new, not yet experienced, way of living or, as expressed by Mercer (2004), 'Becoming a mother involves moving from a known, current reality to an unknown, new reality'.

The need identified by Abrams and Curran (2011) to develop 'new behaviors and skills' results in the need to obtain information. The uncertainty involved in new motherhood often means that new mothers have to learn as they go and deal with new circumstances as they arise (Carolan, 2007). Although many women prepare heavily for motherhood, each mothering experience is different and many women often struggle with having too much information and feeling unprepared at the same time (Carolan, 2007). Advice on issues such as weaning may be conflicting and mothers have to decide whose guidance to follow (Arden, 2010; Brown \& Rowan, 2015) often electing to adopt the advice given by professional experts. Professionals, however, can often be critical of mothers' information seeking attempts (Carolan, 2007). Further, professionals may be restricted by their own practice guidelines or influenced by their own views of acceptable maternal behaviour; for example, many mothers report feeling pressurised by health professionals to breastfeed their children (Cronin, 2003).

Informational support is critical for mothers preparing for their new life role and to enable them to feel confident in their transition to motherhood (Darvill et al., 2010; Leahy-Warren et al., 2012; Loudon et al., 2016) and, as motherhood develops, so do the information practices of individual mothers (D. Greyson, 2015). Mothers and mothers-to-be have many potential sources of information including family, friends, print and broadcast media, health professionals, digital resources and other mothers (Berkule-Silberman et al., 2010). Of these, digital resources are the newest form of information provision for mothers and raises interesting questions about how such resources are used by new mothers.

\section{Internet and motherhood}

The Internet is becomingly increasingly popular as a source of information and a means to communicate with other people. Discussion forums are a particular resource used by many young mothers. Madge 
and O'Connor note that online sources can provide a sense of empowerment for women in the transition to motherhood (Madge \& O'Connor, 2006). Discussion forums prioritise experiential knowledge over other forms of knowledge but can act as a 'lay referral system' by which participants can identify where offline support should come from (Doyle, 2013). The experiential nature of advice on forums can be valued to such an extent that mothers may seek advice on whether to seek medical treatment from participants in online forums rather than 24-hour, free medical advice phone lines staffed by professionals due to the status (as mothers) of participants rather than their medical knowledge (Doyle, 2013). However, as Bouche and Migeot (2008) explain, forums and the Internet typically act as a supplement to health services rather than a replacement.

Brady and Guerin (2010) note that parenting websites can be places where mothers develop a better understanding of what it means to be a parent. In a study of mothers' use of a community parenting forum, Hall and Irvine (2009) found many positives including developing community connections, providing emotional support and sharing informational support. This community aspect of internet forums can be particularly useful in helping mothers in difficult situations; for example Moore and Ayers (2016) found that women suffering from post-natal depression benefited from visiting forums as they could develop a shared understanding and discourse about their illness.

Although there have been several studies of what information needs mothers have in the early stages of motherhood, young mothers have been neglected in the research conducted to date. An exception is the recent, rich ethnographic studies by Greyson and colleagues on information practices of young parents (Devon Greyson, 2017; Devon Greyson, O'Brien, \& Shoveller, 2017) which have provided valuable insights into the information worlds of young parents. These studies, however, only focussed in detail on health related needs, leaving aside the wider needs faced by young parents. Whilst all mothers need strong social and informational support, young mothers needs may be different to older mothers (Cronin, 2003) and their general lack of life experience means they may need additional support that is not necessary for other mothers (Robb et al., 2013). The lack of attention in the literature to young firsttime mothers' needs and the increasing use of online forums to support motherhood gives rise to the two main research questions for this paper:

1. What information needs do young first-time mothers present online?

2. In what way do young first-time mothers ask for information online?

\section{Methods}

\section{Data}


Our data came primarily from the NetMums' "Young Parents Support" forum ${ }^{1}$. NetMums is the UK's biggest parenting website containing advice pages, new stories, chatrooms and forums. The "Young Parents Support" forum is specifically aimed at younger parents and is carefully moderated, creating a friendly and information centred environment. Moderation means that NetMums does not have the reputation of some other popular UK sites of permitting cyber-bullying (Pedersen \& Smithson, 2013) which is particularly an issue for young mothers forums because of the potential vulnerability of the posters and the potential stigma that could manifest.

Established in 2000, approximately $40 \%$ of NetMums' participants are from low-income backgrounds (Russell, 2012) and, with several hundred topics being discussed each year, it is an active forum. This site has previously been studied for its benefits for mothers with post-natal depression (O'Mahen et al., 2013) and been the source of a wide range of studies with different research methods (Russell, 2012).

As the "Young Parents Support" forum explicitly focuses on young parents, it is largely based on the needs of people who self-identify as being young parents; overwhelmingly this is young mothers. This forum is not age restricted so mothers who are still legally children (under the age of 16 in the UK) can post. The forum is publicly viewable and allows anonymous posting so posters can protect their identity if posting on potentially controversial topics.

We collected the initial posts for all threads from the NetMums' "Young Parents Support" forum from mid-August 2014 to mid-August 2015 to give a year's sample of posts. From this sample, we eliminated posts where the poster was clearly over 21 years old; states that she has more than one child; is neither a mother nor pregnant; is a relative of a young mother; has decided not to keep her baby or is a father. These restrictions were to retain the focus of our study on young first-time mothers. We use 21 as an upper bound in our dataset as this is the age at which young people obtain full adult rights in the UK. We include posts from those posters who claim to be 21 , as they may have become mothers before the age of 21. There were no posters who stated an age of less than 14 so this becomes a lower-bound on our age range.

All posts were in English. Only two posters explicitly mentioned they were posting from outside of the UK and we eliminated these from our sample. As all posters are from one country we could more easily interpret discussions about health and social care provision against a relatively similar national

\footnotetext{
${ }^{1}$ https://www.netmums.com/coffeehouse/advice-support-40/young-parents-support-500/ 
background. Out of 405 posts, 240 posts from 204 profiles met the criteria for inclusion. We assumed that each profile was from a unique mother or mother-to-be.

We also created a second dataset from the BabyCentre ${ }^{2}$ forum by taking a year's worth of postings covering a similar time period and using similar inclusion rules as for our NetMums' dataset, and obtaining 39 posts from 33 unique posters. This forum has been used in other studies of young parents' information behaviour, e.g. (Jang, Dworkin, \& Connell, 2012; Papen, 2013). BabyCentre is similar to NetMums in that is a moderated, professional forum. However, it does not have a demarcated board for young parents and is less active than NetMums so provides less data. As we explain below this data was used in a validation test of our coding scheme.

Of the combined data, 129 out of 237 posters clearly stated their age or gave sufficient detail to allow us to infer their age. As shown in Table 1, the most common age range was 19-20 with many posters also in the age range 17-18 and with a mean age of 18.7 years. Those under 16 may be more reluctant to provide their age when posting. If the poster did not provide an age, then we assumed she was less than 21 years old given the nature of the forum. We have worked on the assumption that all posters are accurately representing themselves as young first-time mothers.

\begin{tabular}{|l|l|}
\hline age & number of posters \\
\hline 14 & $1(0.78 \%)$ \\
\hline 15 & $3(2.33 \%)$ \\
\hline 16 & $8(6.20 \%)$ \\
\hline 17 & $20(15.50 \%)$ \\
\hline 18 & $19(14.73 \%)$ \\
\hline 19 & $33(25.58 \%)$ \\
\hline 20 & $27(20.93 \%)$ \\
\hline 21 & $18(13.95 \%)$ \\
\hline
\end{tabular}

Table 1: Age distribution of posters who provided an age

\section{Analysis}

We established a multi-stage content analysis process to develop our coding model. Firstly, we derived a set of initial codes from the existing literature, in particular the coding schemes presented in (Loudon

\footnotetext{
${ }^{2}$ http://community.babycentre.co.uk/

7
} 
et al., 2016) and (Gazmararian et al., 2014) whose coding models focused on the health and child development needs of first-time mothers including issues of feeding, sleeping, milestones, pregnancy and post-natal health. As family relationships are a commonly cited issue for young mothers, e.g. (Gazmararian et al., 2014; Swann, Bowe, McCormick, \& Kosmin, 2003) we also included initial codes relating to relationships.

We coded all the NetMums' data using these initial codes both to test their value as codes and to identify missing codes. Many posts are long and discuss multiple topics; sometimes to provide context, sometimes because the poster may be frustrated over multiple issues and sometimes because the poster is not sure of what information might be useful to someone wishing to respond. Our interest was in what information needs young first-time mothers express online, as opposed to what topics they discuss, so we coded at the post level rather than sentence level to treat the whole post as a request for information.

In the second stage of coding, we took an inductive approach examining our posts in detail and developing more fine-grained codes. These sub-codes were based on the content of the posts and range from topics such as relationships to health conditions to legal issues. To code the posts, we tried to determine under what topic a suitable response would fall. In most cases, it was relatively easy to determine this. In some cases, it was more challenging to determine what response was required when it covered more than one topic. A post may, for example, discuss lack of money, leading to poor housing and therefore health issues but the need itself is about finance. In these cases, two members of the project team discussed the post against our existing classification and used the responses to the post as a guide to how the NetMums community had interpreted the post. Once the coding scheme had stabilised we re-coded the whole dataset against the new coding scheme and were then able to assemble the sub-codes under three main thematic codes of (1) child development and health, (2) providing a good environment, and (3) relationships.

We tested the final coding scheme in two ways. Firstly, we took the BabyCentre forum and coded it against the coding scheme derived from the NetMums' data. This revealed no new topics or themes; consequently, we can conclude that our coding scheme, although derived only from NetMums, is valid for other young first-time mothers' forum data. This does not equate to data saturation. However, as our themes arise from a year's worth of postings from a major forum and a year's worth of data from another forum gave rise to no new themes, we believe that our coding and findings are a robust description of the general classes of information needs expressed in these online forums. As this validation test demonstrated that the NetMums and BabyCentre datasets covered identical themes we combined the 
two datasets to give a larger dataset of 279 posts by 237 posters for analysis. Some posts contained no information needs and so were eliminated, resulting in a final dataset of 266 posts by 237 posters.

Secondly, we conducted an inter-coder reliability test. A third member of the project team, who was not involved in the development of the coding scheme, coded a $10 \%$ random sample of the data to test the repeatability of the coding reported below (see Findings section for the detailed results). This test demonstrated the coding scheme was reliable.

\section{Findings}

The three major themes that arose from our analysis of the forum dataset along with the derived subcodes are summarised in Table 2, which shows how many posts were coded under each theme and subcode. The column $\%$ in Table 2 gives the percentage of all posts that are coded with each sub-code. We coded each post under one sub-code only.

It became clear early in the analysis that posts presented needs in one of two distinct ways. One type of post belongs to what Taylor called conscious needs where the poster realises that they need help or information but is not yet able to form a distinct question to be answered (Taylor, 1968). As described by Taylor, these posts are often 'ambiguous and rambling' being long, multi-faceted and ending with vague requests such as 'could anyone help', 'has anyone been in this situation', or no direct request at all. These posters often seem to be thinking their way through a problem or hoping that someone else can turn their situation into a question that can be answered. We refer to these needs as Situational Needs as the posts typically describe a situation faced by the poster rather than a distinct information need.

The other type of post corresponds to Taylor's (1968) definition of a formalized need or 'a qualified and rational statement of his question.' and are more likely to be shorter, more succinct statements of a direct information need. As these posts contain clear questions or statements of need they are easier to classify topically. We refer to this type of posts as Informational Needs. An inter-coder reliability test showed a Cohen's Kappa coefficient of 0.87, a strong agreement strength on which needs are Informational and which are Situational.

These two types of needs are different modes of making a request and the balance between Informational and Situational Needs differs across the themes and sub-codes identified during the analysis. Informational Needs however predominate in the dataset as a whole. Below we present each theme and the sub-codes within them outlining what kind of information is sought in each. An inter- 
coder reliability test showed a Cohen's Kappa coefficient of 0.62 , good agreement strength on the topics of posts (Landis \& Koch, 1977). Most disagreement came from a small number of posts where it was not clear if the post had a topical need at all or the poster was simply expressing a difficult emotional situation.

\begin{tabular}{|c|c|c|c|c|}
\hline Thematic codes & Sub-codes & $\begin{array}{l}\text { Information } \\
\text { al }\end{array}$ & $\begin{array}{l}\text { Situation } \\
\text { al }\end{array}$ & $\%$ \\
\hline \multirow[t]{2}{*}{$\begin{array}{lll}\text { Child development } & \text { and } \\
\text { health } & & \\
\end{array}$} & Child development & 31 & 3 & $\begin{array}{l}12.78 \\
\%\end{array}$ \\
\hline & Health & 24 & 11 & $\begin{array}{l}13.16 \\
\%\end{array}$ \\
\hline Sub-total & & & & $\begin{array}{l}25.94 \\
\%\end{array}$ \\
\hline \multirow[t]{6}{*}{$\begin{array}{lll}\begin{array}{l}\text { Providing } \\
\text { environment }\end{array} & \text { a } & \text { good } \\
\end{array}$} & Education & 3 & 12 & $5.64 \%$ \\
\hline & Finance & 21 & 3 & $9.02 \%$ \\
\hline & Housing & 6 & 9 & $5.64 \%$ \\
\hline & Legal & 6 & 3 & $3.38 \%$ \\
\hline & Professional support & 9 & 7 & $6.02 \%$ \\
\hline & Working and maternity leave & 3 & 5 & $3.01 \%$ \\
\hline Sub-total & & & & $\begin{array}{l}32.71 \\
\%\end{array}$ \\
\hline \multirow[t]{2}{*}{ Relationships } & $\begin{array}{ll}\text { Managing } & \text { existing } \\
\text { relationships } & \end{array}$ & 13 & 24 & $\begin{array}{l}13.91 \\
\%\end{array}$ \\
\hline & Making new relationships & 54 & 19 & $\begin{array}{l}27.44 \\
\%\end{array}$ \\
\hline Sub-total & & & & $\begin{array}{l}41.35 \\
\%\end{array}$ \\
\hline Total & & $170(67 \%)$ & $96(36 \%)$ & $100 \%$ \\
\hline
\end{tabular}

Table 2: Codes covering information and situational needs

\section{Child development and health}

Our first theme, containing around $26 \%$ of posts, is on child development and health.

Informational child development posts ask questions around child development or behaviour. These are typically short with a clear question, many of which are based around what is seen as normal (e.g. normal time to toilet train, normal stance for a young child, normal age to start walking) or what is seen as best (e.g. best food to give a young child, best brand of formula milk). Some queries are also around challenging behaviour and how to deal with this. The most common relate to sleeping, feeding, behaviour and milestones with a typical example being '...he is also waking up several times a night hungry. does this mean his system is ready for something more substantial?'. 
Situational child development posts are far fewer than informational posts and express generalised anxiety about a relatively long-term situation such as a child's weight or eating patterns rather than a direct question. Examples include: 'Im really worried that if $i$ go and hes underweight what would happen. I know I have to go but i suffer anxiety and always feel i need to look like $i$ know what im doing and try do everything right/perfect (i know nobody is perfect).'.

Informational health posts are typically short with a clear information need on a health topic, e.g. what should one feed a child recovering from a short illness, is it safe to take a child with chicken-pox swimming, is something different about a child, such as a rash, a cause for concern? Examples include: 'Hi hope someone can help my little girl is 10 month old and she has stared dropping her head forward all the time what is it and why is she doing it $x x$ ' and 'My sons winky within the past few hours (as I write this it 19:31) has become almost purple looking.'

Situational health posts present vague concerns without specific questions which may reflect a state of uncertainty around a medical condition, future events such as childbirth, or what does or does not seem normal such as 'just looking for advice or if anyone else's baby has done this he was also born with meningitis but has pulled through that don't know if it's relevant or not thanks'.

\section{Providing a good environment}

The core of this theme is how to create and maintain a good (as defined by the mother) home for a child. This includes questions on finance, legal issues, education, work, dealing with professional services and issues around housing. Work-related needs, in particular maternity leave, are included here as the expressed intent behind these needs is to improve the child's environment, e.g. obtaining a new job to improve the family finances. This theme also includes interactions with professional services, such as health visitors, trained nurses or midwives who regularly visit all new mothers, primarily focussing on health or child development but who can also provide a liaison with other state services. $33 \%$ of the posts were within this theme.

Almost $6 \%$ of posts ask about education. Education posts are typically about prospective education and are focussing on the aspirational elements of education. Sometimes, as in the case of informational education posts they contain specific questions about education, including seeking advice on courses, student financial support, student housing and implication of continuing education such as stress. These requests can refer to school, college, or university. Requests on apprenticeships are coded under Work and Maternity Leave as they refer to work-based training. A typical post is: 'Does anyone in the glasgow 
area know any courses even ones that don't pay that can get me a step close to getting where $i$ want to be in life?'.

Situational education posts discuss potential educational opportunities including whether to return to education whilst their child is young, and asking whether it is the right time to continue with education, or seeking reassurance that education is the right choice. Many are looking for people who have been through similar experiences to help with returning to education as in this example, 'Can anyone share some stories similar to mine or give me some motivation (as I lack a lot of it) to go back to the same college a third time!!'.

Almost $10 \%$ of posts were about financial topics, most were classified as informational finance posts, asking for information on benefits such as working, tax credits, child care, or advice on financial problems such as the cost of childcare or baby items. This also includes queries about financial aspects of housing such as claiming housing benefits. Most posts simply asked questions along the lines of 'does anyone know if I am entitled to any help' which, in the context of most posts, means 'am I entitled to any benefits' reflecting a general lack of knowledge about state benefits for young mothers. Examples include: 'Every tax year you get a double payment, so was wondering if it was at the end of the tax year so it would be April ??'.

A small number of posts were situational finance, detailed narratives where financial topics dominated. In these posts, the posters appeared to be struggling to find information about benefits, confused about benefit entitlements, or uncertain about their changed financial situation. Example: 'Today I received my first income support payment and I received $£ 65.55$ and I'm incredibly confused as it has been a couple of days and I have received nothing in the post to explain this.'

Almost 6\% of posts required information on housing. Questions on housing benefits were coded under Finance. Informational housing posts explicitly requested information on housing issues such as seeking advice on how to rent, questions about housing repairs, and the rights and responsibilities of tenants and property owners such as 'pls is any one knows how I can manage to rent a small flat, just for me and my son?', and 'Does anybody know if you can get away with not telling the estate agents I am not returning to work and claiming full $H B$ [Housing Benefit]?'

Situational housing posts gave accounts of living situations and ask for help rather than posing a question. The posts are often long, describing difficult housing situations with possible housing options that may each have difficult consequences such as leaving the parental home, ending a relationship, or 
moving city. An example of this is: 'my boyfriend wants me to move down to Essex were his mum IIves so we can be close to support and he can keep his job in London. The only problem is my family...they will go absolutely mental and practically disown me. Iv really got no idea what to do at all...anybody got any suggestions on what I can do...' Even if the poster and her child are living with friends or with their partner's family, the poster may count as being officially homeless, a legal status which increases their chances of obtaining state housing and losing this status, which along with the increased housing priority status, is a recurrent concern within this group of posts. This was one of three categories with more Situational than Informational needs.

A small number of posts were on legal issues. Informational legal posts request information on legal matters including name changes for the mother or her child, issues of family access, divorce and separation, and legal issues arising from housing such the legal process of eviction. Examples include: 'I was wondering if he could be able to win the custody?' and '... would I be able to do a last name change without his consent?'

Situational legal posts provide considerable detail about legal issues, but make no specific request for information. Such posts often ask for advice or ask for connections to other young mothers as sources of advice. Legal systems can be complex to navigate without help and the situational requests gave rich descriptions of situations where legal advice is required even if not explicitly requested, for example, on how to restrict paternal access to a young child. Although several posts hint at intimate partner violence, no posts ask for advice on this issue except on how to restrict a violent partner's access to the child. Posts may also describe where a legal situation, such as parental criminal behaviour, may have consequences for the poster's position as a parent. As with other situational posts, often the poster can only ask about others' experience in similar situations as shown in these two example: '[after long presentations of legal situations] I know this sounds like a statement rather that a question but if you were in my position what would you do, or does anyone have any advice for me?' and 'I was just wondering what other people would do in this kind of situation. Sorry this is a bit of an essay.'

About 6\% of posts are about Professional support. Informational posts ask questions about the role of support services, questions about how to interact with professionals (e.g. do they attend counsellors alone), and about the quality of support (e.g. should they be receiving specialist support). In some cases, posters stated they were asking for information online to avoid asking professional sources of advice such as health visitors. This may be a way of 'safety-checking' a legal position before revealing a need to a professional, for example 'Hi all my new baby's dad does drugs and I want to tell the health visitor in case something comes up later on. But what are the implications of telling $h v$ [health visitor]?' 
Situational posts often describe situations where problematic interactions with professional services are giving cause for worry. Most commonly, the poster is concerned that she will lose custody of her child even if there is no specific reason for this concern, whilst other posters are expressing situations where they feel let down by specific professional services. Examples include: 'is asking for help from things like home start or a caf for support mean im a terrible mum and i cant cope...' and '...My social workers have reassured me that they won't be taking the baby away from me or anything drastic, they just want me to have the full support. Is there any other teen moms on here?? This is obviously my first child and I am so scared!! Xx'.

The final code in this theme was work and, in particular, maternity leave. Maternity leave is a legal right in the UK, however leave entitlement and financial support during maternity leave varies according to an employee's status and there are different types of maternity leave open to employees, which makes it a complicated area. There were only a few posts in this category, perhaps because most posters had not yet obtained employment before starting a family. Informational working posts asked questions about work-related maternity rights such as maternity leave and maternity cover, for example ' $i$ was wondering how much time a 16 year old would be allowed for maternity leave before and after pregnancy?'.

Situational working posts ask about getting a job, which may be their first job, how to deal with work problems arising from pregnancy or having a child, how to cope with the transitions from work to nonwork, and financial implications of pregnancy. In this category it was noticeable that informational posts were by mothers in work whereas situational posts were by mothers not in work. These posts contained a strong sense of being unable to cope: ' $i$ am 17 and I don't know how I am ment to work when company's wont take me I am with my partner that is on minimum wage but im stuck at home all day and it getting me down iv looked for work at home jobs but cant seem to find any, any help???'

\section{Relationships}

Our final theme contains posts about personal relationships. It is the most populous theme containing $41 \%$ of the posts. We divide relationships into posts about existing relationships and new relationships; in both cases, posters wish to improve their own situation by either by making new friends or improving existing relationships that are currently causing concern.

The second most common topic in our dataset was Managing existing relationships with almost 14\% of posts in this sub-code. Both information and situational posts are long, complex posts describing 
situations, however informational posts have a clear need such as how to inform a parent of a pregnancy, how to help a partner bond with a new child or how to communicate with a partner. Many posts are seeking reassurance about a feeling or request advice by asking about what is perceived as being normal with statements such as 'has any one else's partner being the same?'

Situational posts are also often long complex posts but are vague on what advice is needed or might help. Many posters are looking for advice on a situation, some asking for others' insight, whilst in other posts there are direct questions such as 'am I wrong in doing this' but without any clear guidance as to what behaviour is being referred to. Many of these posts indicate that the posters are distinctly unhappy in a current relationship (most often with the baby's father, and/or the young mothers parents or the baby's paternal grandparents) and who don't know where to start with finding a solution as in this post 'I'm not sure what I'm looking for in posting this I guess I'm just looking for people who understand me who may have gone through something similar. Just feeling really lonely in this situation.'

Many young first-time mothers want to meet other young mothers and the most common request in our dataset was informational making new relationships posts, typically short posts requesting to meet other young mothers. Example: 'Would love to get to know other young mums in the croydon/south london area as none of my close friends have kids...'

Situational making new relationships posts are longer posts that describe a complex situation, usually expressing isolation, and looking to connect to new people. These posts do not ask to meet or connect with new young mothers explicitly, but instead use indirect experience-based requests such as 'wondering if anyone has any helpful tips or advice for first time mums'.

\section{Discussion}

\section{What information needs do young first-time mothers present online?}

Our first research question was on the information needs expressed online by young first-time mothers. Our data comes from young mothers under the age of 21 , and it useful to contrast against others' findings from other demographics. In Table 3, we present our main codes and map these to the codes/themes uncovered by several recent, complementary studies on mothers' information needs against our codes to identify where our scheme has unique codes and where codes from other studies are not present in our data. For ease of comparison, we have separated out some of the key needs which fall within our three themes: those relating to child development and health appear at the top of the table; followed by needs that relate to creating a good environment; and finally relationships appear in at the bottom. 


\begin{tabular}{|c|c|c|c|c|}
\hline Current study & $\begin{array}{l}\text { (Gazmararian, } \\
\text { Dalmida et al. 2014) }\end{array}$ & $\begin{array}{l}\text { (Loudon, } \\
\text { Buchanan et al. } \\
2016)\end{array}$ & $\begin{array}{l}\text { (Nicholas and } \\
\text { Marden 1998) }\end{array}$ & $\begin{array}{l}\text { (Porter \& Ispa, } \\
\text { 2013) }\end{array}$ \\
\hline $\begin{array}{l}\text { Child } \\
\text { development }\end{array}$ & $\begin{array}{ll}\text { - } & \text { Nutrition and } \\
\text { (breast) feeding } \\
\text { - Nurturing/develop } \\
\text { ment }\end{array}$ & $\begin{array}{l}\text { - } \text { Milk feeding } \\
\text { - } \quad \text { Products and } \\
\text { Recommendati } \\
\text { ons } \\
\text { - Sleeping } \\
\text { - Weaning }\end{array}$ & $\begin{array}{ll}\text { - } & \text { Child } \\
\text { behaviour } \\
\text { - } & \text { Child } \\
& \text { development }\end{array}$ & $\begin{array}{ll}\text { - } & \text { Feeding/eat } \\
\text { - } & \text { Sleep } \\
\text { - } & \text { Developme } \\
\text { nt } \\
\text { - } \text { Discipline } \\
\text { - } \text { Toilet- } \\
\text { training } \\
\text { - } \text { Mother- } \\
\text { child } \\
\text { relationship } \\
\text { - Normality }\end{array}$ \\
\hline Health & $\begin{array}{l}\text { - Healthcare access } \\
\text { and utilization } \\
\text { - Stress and mental } \\
\text { health }\end{array}$ & $\begin{array}{l}\text { Health and } \\
\text { Infant Care }\end{array}$ & $\begin{array}{l}\text { - Health for } \\
\text { parent } \\
\text { - Health for } \\
\text { the child }\end{array}$ & - Not present \\
\hline Education & Not present & Not present & $\begin{array}{l}\text { Careers, } \\
\text { education } \\
\text { and training }\end{array}$ & Not present \\
\hline Finance & Not present & Not present & $\begin{array}{l}\text { - } \quad \text { Child care } \\
\text { - Money }\end{array}$ & $\begin{array}{l}\text { Not present } \\
\text { Not present }\end{array}$ \\
\hline Housing & Not present & Not present & - Environment & Not present \\
\hline Legal & Not present & Not present & Not present & Not present \\
\hline $\begin{array}{l}\text { Working and } \\
\text { maternity leave }\end{array}$ & Not present & Not present & $\begin{array}{l}\text { Careers, } \\
\text { education } \\
\text { and training }\end{array}$ & Not present \\
\hline $\begin{array}{l}\text { Professional } \\
\text { support }\end{array}$ & 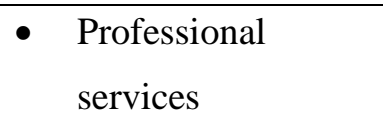 & Not present & $\begin{array}{ll}\text { - } & \text { Child care } \\
\text { - } & \text { Environment }\end{array}$ & $\begin{array}{ll} & \text { Advice } \\
\text { from others }\end{array}$ \\
\hline
\end{tabular}




\begin{tabular}{|c|c|c|c|c|}
\hline Relationships & $\begin{array}{l}\text { - Family/cultural } \\
\text { influence } \\
\text { - Relationships/supp } \\
\text { ort }\end{array}$ & - Family & Not present & $\begin{array}{l}\text { - Advice } \\
\text { from others }\end{array}$ \\
\hline Absent codes & - $\quad$ Safety & - Activities & - School & 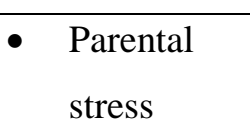 \\
\hline
\end{tabular}

Table 3: Comparison of codes in Table 2 against themes derived in complementary studies

Table 3 is instructive in situating our analysis in the context of the wider literature. In doing so, the first finding which becomes immediately apparent is the consistency to which information needs relating to our first theme of child development and health are identified in studies of mothers' information needs. For example, almost all of the codes identified by Porter and Ipsa (2013) in their study of online forum posts made in 2007 by mothers of 0-2 year olds, who had an average age of 26, appear under this theme. Similarly, this theme is pronounced in the work of Gazmararian et al. (2014) who conducted focus groups with new mothers aged 18-42, generating rich data from mothers' own experiences, which informed our own coding model. Writing within a UK context, both Nicholas and Marden (1998) and Louden et al. (2016) found strong evidence of these information needs in their group interviews with mothers; and again the latter study in particular was informative in developing our own coding scheme.

The codes falling under our second theme of "providing a good home" appear more sporadically in the existing literature. For example, many of these themes, particularly around legal, housing, education and finance were not present in the scheme adopted by Louden et al. This may be, as the authors note, because they were working with a sample of largely university educated, older mothers (average of 29 years old) who have greater access to stable housing, employment, and financial maternity support. The scheme adopted by Nicholas and Marden is perhaps the most similar to ours in this respect, in that it covers a wider set of needs than child development and health, including codes for Environment (covering issues like housing) and Education/Work. Their scheme also includes the code of School (covering issues such as how to select a school and home education), which was not present in our data. This likely reflects their focus on mothers of children aged under five, while the mothers in our data had children who were far younger than school age.

The need for information relating to professional support was the only code under this theme identified in the other studies included in Table 3. For example, while the work of Gazmararian et al. (2014) is 
largely focused on mothering activities, they identified both information needs relating to parenting (e.g. 'What/how much to feed') and also problems with information sources, such as 'Dealing with discrepancies/discrepant information'. Similarly, Porter and Ipsa (2013) highlighted issues of parental stress (which we included under health), and a code relating to advice from others where mothers were challenging advice from information sources. Interestingly, Louden et al. had (2016) the code of 'Activities', which could comfortably fit under this theme, but that we did not identify in our data. None of our sample requested information on activities for taking children and only mentioned baby groups negatively due to feeling judged by other mothers, and none requesting information on new groups.

The theme of relationships is also less pronounced in the other studies than in our data. When this code appears, it often relates to questions as whose advice should be followed, as it does in Porter and Ipsa's scheme. There are also examples of this theme manifesting in quite different ways than in our coding scheme. For example, while Gazmararian et al. (2014) identified the code of safety, this refers mostly to physical safety (e.g. how to correctly use a car seat) whereas in our data, safety concerns were mostly about well-being issues arising from poor parenting by partners or extended family. Similarly, Louden et al. apply the code of family to issues of child care, returning to work, and family finance, rather than the more personal and complex relationship issues captured in our data. Their lack of codes around more problematic issues such as isolation and difficult relationships may have arisen due to the fact that the mothers were recruited from a supportive mothering group and/or that mothers may be less inclined to present difficult or negative situations in interviews.

Reading across these studies, there does appear to be a core set of topics that are important to mothers: child development (both in the sense of developmental stages and 'mothering' activities such as sleeping and weaning), child health and relationships with other people. These are relevant to all mothers and therefore not surprising that they appear across studies. Other categories, such as education needs, are specific to the group of mothers who have taken part in the studies, whilst other differences may result from the methods used to gather data.

Our coding scheme appears far wider than others available in the literature and the use of forum data has provided evidence of difficult sensitive issues around relationship needs notably absent in other studies utilising more traditional interpersonal data gathering methods. Some differences in our data may have arisen from different methods, some because young first-time mothers do have different and more complex needs than older mothers. Older mothers, as shown in the Loudon et al. study will often have existing housing, work, finance and stable relationships in place before becoming mothers; young first-time mothers will often need to think through these things at the same time as becoming mothers 
resulting in a more complex pattern of needs. This would imply that younger mothers have to expend more time thinking through problems - and require more support in doing so - and therefore this might explain the high level of Situational Posts in some of our themes.

\section{How do young first-time mothers ask for information online?}

This argument that young mothers may have more complex needs than older (and often more affluent) women who are the focus of much of the existing literature is also reflected in the ways in which young women express their information needs in Internet forums. This was the focus of our second research question, which sought to investigate how young first-time mothers asked for information online.

The concept of information needs has been suggested to be theoretically ill-defined (Savolainen, 2017), with Lundh (2010) arguing that information needs themselves are difficult to investigate and it is easier to investigate information behaviours and activities arising from information needs rather than the needs themselves. Early discussions on information needs, e.g. (Belkin, Oddy, \& Brooks, 1982; Wilson, 1981) revealed a dissatisfaction with information need being the focus of inquiry rather than the problems that give rise to needs. That people in problematic situations need to be able to express some kind of need in order to receive help has, however, resulted in information need being a core concept in information seeking research, even if it lacks a clear definition.

In our study, we examined the texts that young mothers provided as statements of need. Despite the conceptual ambiguity noted above, this provided a theoretical framework that allowed us to distinguish between informational and situational posts: that is posts where an information need was presented, and posts where a situation was presented but without specific information need. These were described above as corresponding to the Taylor's (1968) conscious and formalized information needs and seemed, as with Taylor's classification, to distinguish between cases where the poster could identify what information she needed (Informational needs) and cases where the poster could not yet formalize her need into an information need (Situational needs).

Notably, situational posts are significantly longer than informational posts (205 words on average for situational posts vs. 95 words on average for informational ones, $\mathrm{p}<0.001$ Mann Whitney). This reflects, we argue, that the young women writing these situational posts are in the very early stages of identifying or expressing a specific need. Indeed, how we move from problematic situations to statements of needs is an interesting area of investigation. As Belkin et al. (1982) proposed, people who have anomalous states of knowledge are "unable to specify precisely what is needed to resolve that anomaly". In the early stages of a problematic situation, we might need to ask someone else about our 
situation. A common method now for doing so is to online and interact with people in discussion groups or online forums (Bowler, Mattern, Jeng, Oh, \& He, 2013). Online interactions can put us in touch with people who have experienced similar situations to us and who can use their experience to help us understand our situation and how we might resolve it.

In this context, then, young mothers appear to be using online forums in two distinct ways. With regard to situational needs, online forums provide a space and opportunity to begin to recognise and/or express needs that are often both sensitive and complex. Conversely, informational posts reflect cases where the poster is moving towards a solution and knows what information is desired, and is therefore able to more concisely articulate what information she requires.

\section{Conclusions}

When faced with an information need we can either ask another person or try to find information ourselves, by interacting with existing information resources or finding new information through search engines. Search engines such as Google allow us to ask about very personal information needs whilst preserving our anonymity but they do rely on us being able to form suitable search requests. Other people, especially experts, can offer tailored advice, help us uncover what information we really need and can contextualise information that we should know even if we have not asked for it directly.

Internet forums offer the potential to gain the benefits of personalised information without the challenges of face-face requests and, if we choose, retaining our anonymity whilst asking for information. They also have the advantage, unlike people, of being readily available to pose questions to (which can at least allow us to feel that we have acted on a problem even if we have to wait on a response), and we can examine responses asynchronously when we are able to deal with responses. They still require a degree of personal compromise as Internet forums often have expected rules of behaviour and risk negative outcomes such as judgment or being ignored. However, given this potential for anonymised, personalised and instantaneous information, it is perhaps unsurprising that they have become a useful and popular way to request information, often on difficult topics. They can also be a useful space for sense-making, particularly around what is 'normal' in a situation (Genuis \& Bronstein, 2016) and this notion of what is 'normal' was very important to many posts in our data set. The interactions on discussion forms can also been seen as a form of what Veinot refers to as collaborative information behaviour with communities sharing their own experience and personal knowledge, (Veinot, 2009) 
This study has looked at the particular context of young first-time mothers and has revealed a rich range of needs that arise in a group of young women at an important life transition. By analysing the posts made to a forum for young mothers, we have generated new insights into the information needs of this group. The needs uncovered in our study fall into three major categories: environment, relationships and child health and development, i.e. home, mother, child. These categories reflect a concentration of information needs around what physical resources it takes to raise a child (environment), what social resources it takes (relationships) and what new knowledge about children in general and her child in particular it takes (child health and development). That these themes are broader than those expressed in the existing literature by older mothers suggest there is a need for greater information resources tailored specifically to this group, both online and in other formats.

Not only were a wide range of needs expressed by our participants; these also took two distinct forms. While some young mothers made informational posts, where they were able to clearly articulate the information they required, one-third of the posts we classified as situational posts. These are posts where the poster needed help in structuring her thinking about a problem in order to be able to solve it. For some topics, situational posts were the most common type of post reflecting some areas of life where problems are complex and where the support of another person is needed to achieve resolution. Thus, by reporting multiple, complex and interrelated information needs, often within sensitive situational contexts, this study provides insight into the early embryonic stages of problem recognition and information seeking.

This ability to distinguish between informational and situational posts demonstrates a particular strength of this methodology, as we were able to capture these "provisional" or "partial" information needs, which may be difficult to articulate in an interview or focus group setting. Online forums can therefore help us better understand how early stage information needs are different to later stage information needs. Importantly, the needs are expressed in these forum posts as they are felt. That is people post on what is of current concern, generally as descriptive narratives, rather than reflecting back later. This means the posts are very 'immediate' in providing the context of a person thinking through their situation.

Nevertheless, there also limitations to this methodical approach. Unlike surveys or interviews we cannot ask questions of the participants; neither can we clarify meanings or follow up later. Further, all posters necessarily must have Internet access and sufficient literacy skills to post messages. Consequently, our findings may not be representative of the experiences of young first-time mothers who do not have this access, and may possibly be experiencing greater financial and social marginalisation. Wider social 
context is also important here, as our data came from young mothers in one country and their experience may be different from young women in other countries with different social supports. Topics of need may also vary by age; this is not something we can answer here but is worthy of future investigation.

We used data primarily from the "Young Parents Support" NetMums forums. Young first time mothers may also post to other forums on specialist topics but, as it is rare to provide an age when posting to these other forums, we only worked with this forum which is dedicated to young mothers.

Our data also cannot claim to capture all the needs faced by young mothers, as our participants may also have other needs not currently expressed online. What our data does capture are the needs that were deemed sufficiently important by young mothers to be asked about online, and the experiences of larger numbers of young women than could be reached by more traditional qualitative methods. While posting to an Internet discussion group can be a useful additional source of information, it seems from many posts that there was no-one in their offline environments who could be asked or who could satisfy the posters' needs. That is, many posters seemed to view the online forums as their only source of information. This is an important finding, particularly as many of the needs expressed were often more complex and sensitive than those documented in the existing literature. It suggests that moderated Internet forums can serve as a complementary source of information to offline environments, and potentially a safe space to ask questions and describe difficult situations.

This study therefore expands our knowledge of young mothers' information needs beyond the current studies described above which, in turn, can be used by practitioners to guide the design of information support services. The topics outlined in Table 2 could form the basis of a classification scheme for online parent-support forums to classify the questions posted to the forum, for users to effectively locate Q\&A entries that best match their information needs.

The young women who posted to the forums used in this study were often facing significant challenges in housing, finance, changing relationships, and, often, the negative attitudes of others. Through examining the posts, we can see how they think through their own personal situation and the needs that are arising in order to provide the information necessary to move forward in successful motherhood. These are young women who are not only happy to be mothers and aiming at being successful mothers, they are active information seekers who are taking initial steps to resolve their needs. Appropriately moderated forums, such as the ones used here, targeted specifically toward young mothers are an important tool in supporting these women in finding the information required to achieve this goal. 


\section{Acknowledgments}

This research was funded by ESRC grant ES/L012634/1, Understanding the Information Needs of Young First Time Mothers from Areas of Multiple Deprivation.

\section{References}

Abrams, L. S., \& Curran, L. (2011). Maternal Identity Negotiations Among Low-Income Women With Symptoms of Postpartum Depression. Qualitative Health Research, 21(3), 373-385.

Arden, M. A. (2010). Conflicting influences on UK mothers' decisions to introduce solid foods to their infants. Maternal \& child nutrition, 6(2), 159-173.

Belkin, N. J., Oddy, R. N., \& Brooks, H. M. (1982). ASK for information retrieval: Part I. Background and theory. Journal of Documentation, 38(2), 61-71.

Berkule-Silberman, S. B., Dreyer, B. P., Huberman, H. S., Klass, P. E., \& Mendelsohn, A. L. (2010). Sources of parenting information in low SES mothers. Clinical pediatrics, 49(6), 560-568.

Bouche, G., \& Migeot, V. (2008). Parental use of the Internet to seek health information and primary care utilisation for their child: a cross-sectional study. BMC Public Health, 8(1), 1.

Bowler, L., Mattern, E., Jeng, W., Oh, J. S., \& He, D. (2013). "I know what you are going through": Answers to informational questions about eating disorders in Yahoo! Answers: A qualitative study. Proceedings of the American Society for Information Science and Technology, 50(1), 1-9.

Brady, E., \& Guerin, S. (2010). "Not the romantic, all happy, coochy coo experience": A qualitative analysis of interactions on an Irish parenting web site. Family Relations, 59(1), 14-27.

Brown, A., \& Rowan, H. (2015). Maternal and infant factors associated with reasons for introducing solid foods. Maternal \& child nutrition.

Carolan, M. (2007). Health literacy and the information needs and dilemmas of first-time mothers over 35 years. Journal of Clinical Nursing, 16(6), 1162-1172.

Cronin, C. (2003). First-time mothers-identifying their needs, perceptions and experiences. Journal of Clinical Nursing, 12(2), 260-267.

Darvill, R., Skirton, H., \& Farrand, P. (2010). Psychological factors that impact on women's experiences of first-time motherhood: a qualitative study of the transition. Midwifery, 26(3), 357-366.

Doyle, E. (2013). Seeking advice about children's health in an online parenting forum. Medical Sociology Online, 7(3), 17-28.

Drentea, P., \& Moren-Cross, J. L. (2005). Social capital and social support on the web: the case of an internet mother site. Sociology of health \& illness, 27(7), 920-943. 
Gazmararian, J. A., Dalmida, S. G., Merino, Y., Blake, S., Thompson, W., \& Gaydos, L. (2014). What new mothers need to know: Perspectives from women and providers in Georgia. Maternal and child health journal, 18(4), 839-851.

Genuis, S. K., \& Bronstein, J. (2016). Looking for "normal": Sense making in the context of health disruption. Journal of the Association for Information Science and Technology, 68(3), 750-761

Greyson, D. (2015). Information practices evolving over time: Cases from the young parent study. Paper presented at the Annual Conference of the Canadian Association for Information Science, Ottawa, Ca.

Greyson, D. (2017). Health information practices of young parents. Journal of Documentation, 73(5), 778-802.

Greyson, D., O'Brien, H., \& Shoveller, J. (2017). Constructing knowledge and ignorance in the social information worlds of young mothers. Proceedings of the Association for Information Science and Technology, 54(1), 139-149. doi: 10.1002/pra2.2017.14505401016

Hall, W., \& Irvine, V. (2009). E-communication among mothers of infants and toddlers in a communitybased cohort: A content analysis. Journal of advanced nursing, 65(1), 175-183.

Jang, J., Dworkin, J., \& Connell, J. (2012). Babycenter. com: New parent behavior in an online community. Paper presented at the The Forum for Family and Consumer Issues.

Johns, R., \& English, R. (2014). Mothers influencing mothers: the use of virtual discussion boards and their influence on consumption. International Journal of Web Based Communities, 10(3), 319-338.

Landis, J. R., \& Koch, G. G. (1977). The Measurement of Observer Agreement for Categorical Data. Biometrics, 33(1), 159-174. doi: 10.2307/2529310

Leahy-Warren, P., McCarthy, G., \& Corcoran, P. (2012). First-time mothers: social support, maternal parental self-efficacy and postnatal depression. Journal of Clinical Nursing, 21(3-4), 388-397.

Loudon, K., Buchanan, S., \& Ruthven, I. (2016). The everyday life information seeking behaviours of first-time mothers. Journal of Documentation, 72(1), 24-46.

Lundh, A. (2010). Studying information needs as question-negotiations in an educational context: a methodological comment. Information Research: An International Electronic Journal, 15(4), n4.

Madge, C., \& O'Connor, H. (2006). Parenting gone wired: empowerment of new mothers on the internet? Social \& Cultural Geography, 7(2), 199-220.

Martell, L. K. (2001). Heading Toward the New Normal: A Contemporay Postpartum Experience. Journal of Obstetric, Gynecologic \& Neonatal Nursing, 30(5), 496-506. doi: http://dx.doi.org/10.1111/j.1552-6909.2001.tb01569.x 
McKenzie, P. (2010). Informing relationships: Small talk, informing and relationship building in midwife-woman interaction. Information Research, 15(1), 1.

Mercer, R. T. (2004). Becoming a mother versus maternal role attainment. Journal of nursing scholarship, 36(3), 226-232.

Moore, D., \& Ayers, S. (2016). Virtual voices: social support and stigma in postnatal mental illness Internet forums. Psychology, health \& medicine, 1-6.

O'Mahen, H. A., Woodford, J., McGinley, J., Warren, F. C., Richards, D. A., Lynch, T. R., \& Taylor, R. S. (2013). Internet-based behavioral activation-Treatment for postnatal depression (Netmums): A randomized controlled trial. Journal of affective disorders, 150(3), 814-822.

Papen, U. (2013). Conceptualising information literacy as social practice: a study of pregnant women's information practices. Information Research, 18(2).

Pedersen, S., \& Smithson, J. (2013). Mothers with attitude-How the Mumsnet parenting forum offers space for new forms of femininity to emerge online. Paper presented at the Women's Studies International Forum.

Porter, N., \& Ispa, J. M. (2013). Mothers' online message board questions about parenting infants and toddlers. Journal of advanced nursing, 69(3), 559-568. doi: 10.1111/j.1365-2648.2012.06030.x

Robb, Y., Mclnery, D., \& Hollins Martin, C. J. (2013). Exploration of the experiences of young mothers seeking and accessing health services. Journal of Reproductive and Infant Psychology, 31(4), 399-412. Russell, S. (2012). Social networking research opportunities: the example of 'Netmums'. Journal of Research in Nursing, 17(2), 195-206.

Savolainen, R. (2017). Information need as trigger and driver of information seeking: a conceptual analysis. Aslib Journal of Information Management, 69(1).

Swann, C., Bowe, K., McCormick, G., \& Kosmin, M. (2003). Teenage pregnancy and parenthood: a review of reviews. London: Health Development Agency.

Taylor, R. S. (1968). Question-negotiation and information seeking in libraries. College \& research libraries, 29(3), 178-194.

Veinot, T. C. (2009). Interactive acquisition and sharing: Understanding the dynamics of HIV/AIDS information networks. Journal of the American Society for Information Science and Technology, 60(11), 2313-2332. doi: 10.1002/asi.21151

Wilson, T. D. (1981). On user studies and information needs. Journal of Documentation, 37(1), 3-15. Yardley, E. (2008). Teenage mothers' experiences of stigma. Journal of youth studies, 11(6), 671-684. 